\title{
Motility and chemosensory behaviour of the sulphur bacterium Thiovulum majus
}

\author{
Tom Fenchel
}

Tel: +4549211633 ext. 325. Fax: +4549261165.

Marine Biological Laboratory (University of Copenhagen), DK-3000 Helsingør, Denmark

\begin{abstract}
The swimming track of the sulphur/sulphide-oxidizing bacterium Thiovulum majus is a left-handed helix. The cells modulate swimming speed by changing the tangential speed and/or the pitch and radius of the helix. Whether attached (to a mucous thread) or swimming, the spherical cells rotate around their anterior-posterior axis in a counter-clockwise direction when observed from the posterior pole. Swimming speeds may exceed $600 \mu \mathrm{m} \mathrm{s}^{-1}$, which is 5-6 times faster than recorded for any other bacterium. Thiovulum cells congregate at oxygen tensions of about $4 \%$ atmospheric saturation $(0.85 \mathrm{kPa})$. Cells which accidentally leave the optimum zone make a U-turn within 150-200 $\mu \mathrm{m}$, thus returning to where they came from. This represents a type of phobic response in which the eventual swimming direction is correlated with the initial direction; it is not a true chemotactic response in the sense that the cells can orient themselves in $\mathrm{O}_{2}$-gradients. The $180^{\circ}$-bend of the swimming path is probably accomplished by changes in the rotational velocity component which take place when the cells swim into an adverse environment. The U-turn response allows the bacteria to maintain the characteristic 100-200 $\mu \mathrm{m}$ thick veils which separate the sulphidic and the oxygenated zone in or above sediments. Evidence for a chemosensory response to sulphide could not be found.
\end{abstract}

Keywords: Thiovulum, chemosensory behaviour, motility, oxygen gradients

\section{INTRODUCTION}

The large, spherical sulphur/sulphide-oxidizing bacterium Thiovulum majus has apparently been found only in seawater. It is a 'gradient organism', which depends on the simultaneous presence of sulphide and oxygen, and it forms characteristic white veils at or above the surface of sulphidic sediments. This phenomenon has been described in some detail (La Rivière, 1963; Wirsen \& Jannasch, 1978; Jørgensen \& Revsbech, 1983). Only one species of Thiovulum is recognized, but cell diameters ranging from 5 to $25 \mu \mathrm{m}$ have been reported from different populations. It is also known that the cells rotate around their own axis and that they can attach to surfaces by a mucous thread or stalk. This thread is not directly visible in the light microscope, but bacteria or other small particles which adhere to the stalk reveal its presence. Its existence has also been demonstrated in whole-mount preparations in the electron microscope. It is believed that the mucous thread is secreted by a strange fibrillar

Abbreviation: atm. sat., atmospheric saturation. organelle known as the antapical organelle. The cells are equipped with ordinary prokaryote flagella which seem to cover most of the cell surface (Fauré-Fremiet \& Rouiller, 1958; De Boer et al., 1961; Wirsen \& Jannasch, 1978).

No close analysis of the motile and chemosensory behaviour has been attempted until now. The present paper reports on laboratory studies of the behaviour of Thiovulum in chemoclines. A number of features were revealed which are unusual or unique among prokaryotic organisms and a novel type of motile response to changes in the chemical environment was discovered.

\section{METHODS}

The material was collected in the innermost part of Nivå Bay (about $15 \mathrm{~km}$ south of Helsingør, Denmark) at water depths between 5 and $50 \mathrm{~cm}$. White patches of sulphur bacteria with the underlying sediment were collected in 0.25 or 0.51 jars and covered by $5-10 \mathrm{~cm}$ seawater. The jars were placed in the dark with a loose lid or sometimes bubbled with atmospheric air. After a day or two, white veils of Thiovulum developed and could be collected with a pipette for experiments. Due to their chemosensory behaviour, cells can be collected with a minimum 

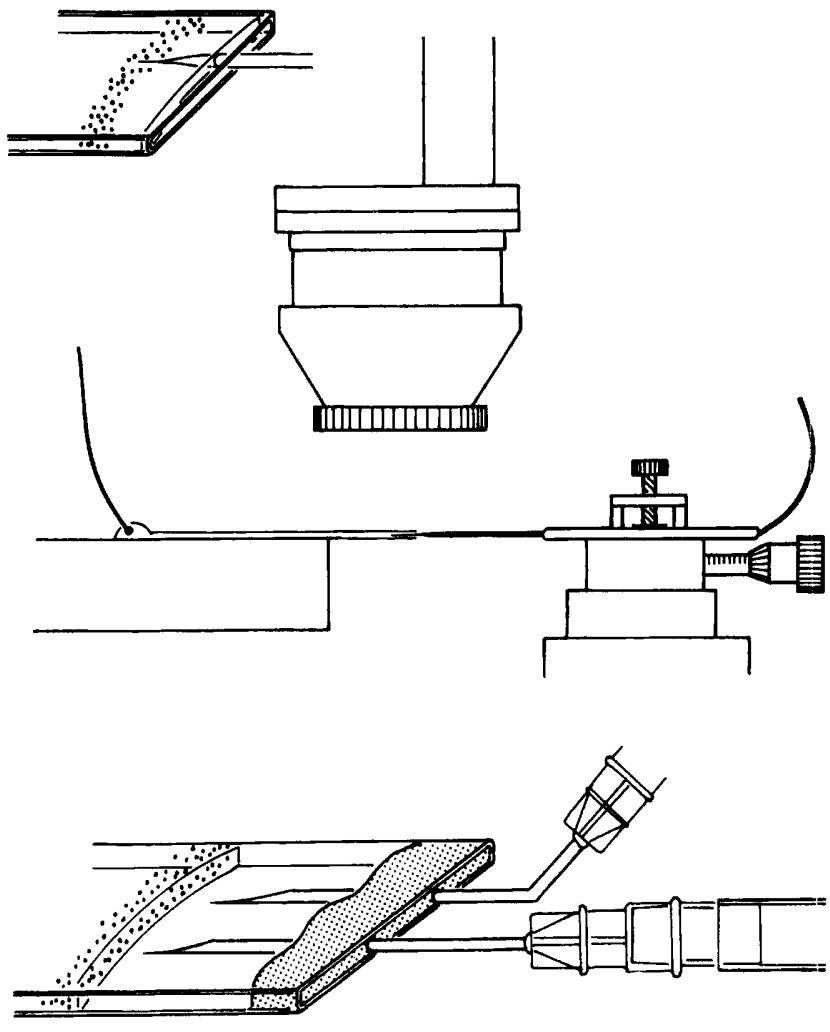

Fig. 1. Above: a capillary microslide illuminated from below and with an oxygen microelectrode inserted on the right side and with contact (via a drop of seawater) to a reference electrode on the left side. The distribution and swimming tracks of the cells were recorded with a CCD-camera mounted on the dissection microscope. Below: hypodermic needles inserted and sealed in a capillary microslide for making rapid changes in headspace gas composition.

of contamination with other prokaryotic or eukaryotic microorganisms. At intervals of $2-3 \mathrm{~d}, 5-10 \mathrm{ml} \mathrm{O}$-free $10 \mathrm{mM}$ sulphide solution in seawater (neutralized to $\mathrm{pH} 7 \cdot 5$ ) was injected into the sediment with a syringe. In this way, the jars remained a reliable source of Thiovulum for more than a month. Cell diameters ranged between 5 and $10 \mu \mathrm{m}$ (mean $7 \mu \mathrm{m}$ ).

Most studies on the behaviour in $\mathrm{O}_{2}$-gradients were made on cell suspensions in capillary 'microslides' (Camlab). These flat glass capillaries show a minimum of optical distortion and they have internal dimensions of $4 \times 0.4 \mathrm{~mm}$. The slides were: completely filled with a suspension of Thiovulum cells. Withir 15 min the cells had consumed the $\mathrm{O}_{2}$ which was initially present in the capillary and they then congregated to form a. narrow band close to the meniscus. The distance of the bands from the meniscus is a function of the $\mathrm{O}_{2}$-consumption of the cells (i.e. cell density), their preferred value of $\mathrm{O}_{2}$-tension and the steady-state diffusion gradient formed by the $\mathrm{O}_{2}$-flux from the meniscus to the bacteria.

The $\mathrm{O}_{2}$-gradient was quantified by inserting oxygen microelectrodes (Diamond Electro-Tech, \#723) from one end of the capillary using a micromanipulator (Fig. 1). The electrodes had an approximately $5 \mu \mathrm{m}$ diameter sensing tip. A reference electrode (an AgCl-coated Ag-wire) made contact with the seawater at the other end of the capillary. A polarization voltage $(0.75 \mathrm{~V})$ was applied and the current was measured with a picoammeter. The electrodes were calibrated in seawater with 100 and $0 \%$ atm. sat., respectively. The $\mathrm{O}_{2}$-tension was recorded at intervals of $50 \mu \mathrm{m}$ from the meniscus and until a zero-reading was obtained somewhere behind the bacterial band.

The distribution and motility of the bacteria were recorded on a video tape during the $\mathrm{O}_{2}$-measurements. A CCD-camera (Panasonic) mounted on a dissection microscope connected to a recorder (Panasonic AG 6200) and a monitor was used. The distribution of the cells could be determined later from individual frames of the recordings. By displaying successive frames (time interval: $40 \mathrm{~ms}$ ) on the monitor, the movements of individual cells could be followed and marked on a transparent overlay attached to the monitor screen (Fig. 2). Parameters such as swimming speeds and the shape of trajectories could then be analysed later. Recordings were made of eight preparations in which the $\mathrm{O}_{2}$-gradients were measured and more than 100 swimming tracks were analysed. These and all other experiments were carried out at room temperature $\left(\approx 20^{\circ} \mathrm{C}\right)$. Additional recordings of swimming or attached cells were made in microscopic preparations with $\mathrm{O}_{2}$-gradients or in water with a known, homogeneous $\mathrm{O}_{2}$-tension and with the CCD-camera mounted on either a dissection or a compound microscope. The angular velocity of attached cells could be established due to the irregular distribution of intracellular sulphur-droplets. It was not possible to obtain good quantitative estimates of the rotation of swimming cells because the shape of their swimming track (a helix) meant that cells were periodically out of focus, when observed with high-aperture lenses.

The analysis of three-dimensional trajectories on the basis of their two-dimensional projections has shortcomings. Ideally only trajectories which are perfectly parallel to the plane of observation should be included. In practice only trajectories which remained in focus for at least two periods of the helical trajectories were included. In the worst case (lowest magnification used, smallest pitch) this should exclude trajectories with an angle exceeding about $30^{\circ}$ relative to the plane of observation. The result of including trajectories which are not perfectly parallel to the plane of observation is a systematic, but relatively small underestimation of mean swimming velocity and of pitch, and an overestimation of the variance. However, the demonstration of changes in these parameters as a function of different $\mathrm{O}_{2}$-tensions is not seriously affected by this shortcoming.

Cells which swam in water with a homogeneous $\mathrm{O}_{2}$-tension rarely changed direction of swimming, tangential velocity or pitch. Tangential velocity $(v)$ was calculated as the mean change in the position of cells in successive frames of the video recordings $(40 \mathrm{~ms})$. Pitch $(p)$ was measured as the distance between two maximum amplitudes of the projected trajectories and the period $(T)$ from the corresponding number of frames. The velocity along the axis of the trajectories $\left(v_{t}\right)$ was determined as $p / T$. The radius $(r)$ of the trajectories was measured as the distance from the axis of the projected trajectories and the maximum amplitude. Since $r$ is always small this estimate is crude relative to those of the other parameters.

The response to a sudden change in $\mathrm{O}_{2}$-tension was studied in capillary slides in which two $0.4 \mathrm{~mm}$ hypodermic needles were inserted and sealed with Araldite in one end of the capillary (Fig. 1 ). The capillaries were filled with a cell suspension leaving about $4 \mathrm{~mm}$ headspace in the end with the needles while the other end was sealed without any headspace. The needles were connected via tubing and a three-way valve to two syringes containing different $\mathrm{N}_{2}$ /air mixtures. In this way the composition of the headspace gas could be changed within about $0.5 \mathrm{~s}$. When the headspace was filled with $4 \%$ atmospheric air in 
$\mathrm{N}_{2}$, the bacteria migrated to the meniscus. If some detrital particles had been included in the preparation the bacteria attached themselves close to the meniscus. By suddenly changing the $\mathrm{O}_{2}$-tension of the headspace (e.g. to $100 \%$ atmospheric air) the response of cells situated within $100 \mu \mathrm{m}$ from the meniscus could be recorded during the following few seconds.

\section{RESULTS}

\section{General motility patterns}

The swimming path of Thiovulum cells is always a lefthanded helix (Fig. 2); the cells have defined anterior and posterior poles (the sulphur granules were largely concentrated in the posterior half of the cell) and they are unable to swim backwards or to tumble. (In some populations of Thiovulum, not used in the present study, the sulphur granules are consistently concentrated in the anterior part of the cells; unpublished observation.) While swimming, the cells simultaneously rotate counter-clockwise (when seen from the posterior pole) around their anteriorposterior axis. The swimming path can be characterized by the following parameters: pitch $(p)$, radius $(r)$, period $(T)$, tangential velocity $(v)$ and the angular velocity of the

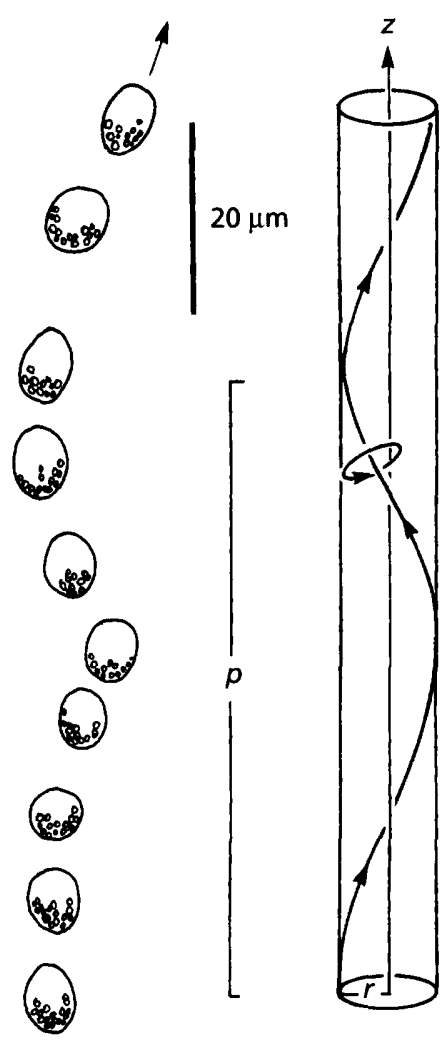

Fig. 2. Right: Properties of (left-handed) helical swimming: pitch $(p)$, radius $(r)$ and tangential and rotational velocity components. Left: Swimming track in the optimum zone of a Thiovulum cell recorded under the compound microscope. Time intervals: $\mathbf{4 0} \mathrm{ms}$. In this particular track the tangential velocity was $330 \mu \mathrm{m} \mathrm{s}^{-1}, r$ was $5 \mu \mathrm{m}, p$ was $65 \mu \mathrm{m}$, and the period $T$ was $0.24 \mathrm{~s}$. The swimming velocity in the $z$-direction was $p / T=$ $271 \mu \mathrm{m} \mathrm{s}^{-1}$. rotation around the axis of the cells $(\omega)$. The radius (ranging from 5 to $40 \mu \mathrm{m}$ ) was small relative to the pitch (ranging from 40 to $250 \mu \mathrm{m}$ ); $T$ varied between 0.2 and $1 \mathrm{~s}$. The velocity in the $z^{\text {-direction }}\left(v_{t}\right.$; see Fig. 2$)$ equals $p / T$ and it is always somewhat lower than the tangential velocity.

Thiovulum cells can modulate their swimming speed $\left(v_{t}\right)$ either by changing the tangential velocity or by changing the pitch and radius of the helix, thus increasing the difference between $v$ and $v_{\mathrm{t}}$ (the ratio varying between $0 \cdot 7$ and 0.95$)$. Tangential swimming velocities ranged from $<150$ to $>600 \mu \mathrm{m} \mathrm{s}^{-1}$. The highest velocities $\left(v\right.$ and $\left.v_{t}\right)$ occurred at $\mathrm{O}_{2}$-tensions which exceeded the optimum value ( $\approx 4 \%$ atm. sat.); the mean velocity was lower in water with an optimum $\mathrm{O}_{2}$-tension and lowest under complete anoxia. In one case (a preparation with an $\mathrm{O}_{2}$ gradient), cells swimming on the $\mathrm{O}_{2}$-side of the optimum zone, those in the optimum zone and those on the anoxic side had mean velocities $\left(v_{t}\right)$ of 422 (SE 15), 244 (SE 20) and 158 (SE 9) $\mu \mathrm{m} \mathrm{s}^{-1}$, respectively. Measurements of swimming velocities in completely anoxic water, however, were irreproducible. In preparations with $\mathrm{O}_{2}$-free water the cells tended to swim more slowly with time and eventually died after several minutes, so the low velocities may be a pathological effect of too long an exposure to anoxia. Cells which swam in water with an optimum $\mathrm{O}_{2}-$ tension tended at intervals to bend the axis of the helical tracks whereas those outside the zone rarely did so.

\section{Attachment}

An optimum $\mathrm{O}_{2}$-tension the cells tended to attach with their posterior pole to surfaces and then secreted a long stalk up to $100 \mu \mathrm{m}$ (Fig. 3c). They seemed to have difficulty in attaching to glass, so that in gradients in the capillary microslides usually less than $10 \%$ of the cells were attached at any moment, but they readily attached to detrital particles. When the cells were attached, translational motion was prevented by the stretched stalk, but rotational movement continued. The angular velocities $(\omega)$ ranged from 20 to $63 \mathrm{~s}^{-1}$ (3.2-10 rotations s $\left.{ }^{-1}\right)$; the highest values, however, were only found as a transient state in cells exposed to changing $\mathrm{O}_{2}$-tension (see below).

At very high cell concentrations the cells tended to aggregate if suspended in water with a high $\mathrm{O}_{2}$-tension. This phenomenon is probably initiated by random fluctuations in cell density. Small volumes of water containing above-average concentrations of cells will have a relatively reduced $\mathrm{O}_{2}$-concentration due to respiration. More cells will then be trapped within this volume due to their chemosensory behaviour and so the aggregates will grow with time until all cells are found within one or a few large aggregates. In such suspended swarms the cells produced mucous threads which often became entangled so that lumps of interconnected cells appeared without being anchored to surfaces (Fig. 3b). This mechanism was sometimes partly responsible for the coherence of the characteristic veils suspended above sulphidic sediments (Fig. 3a), but only if cell densities were very high. 

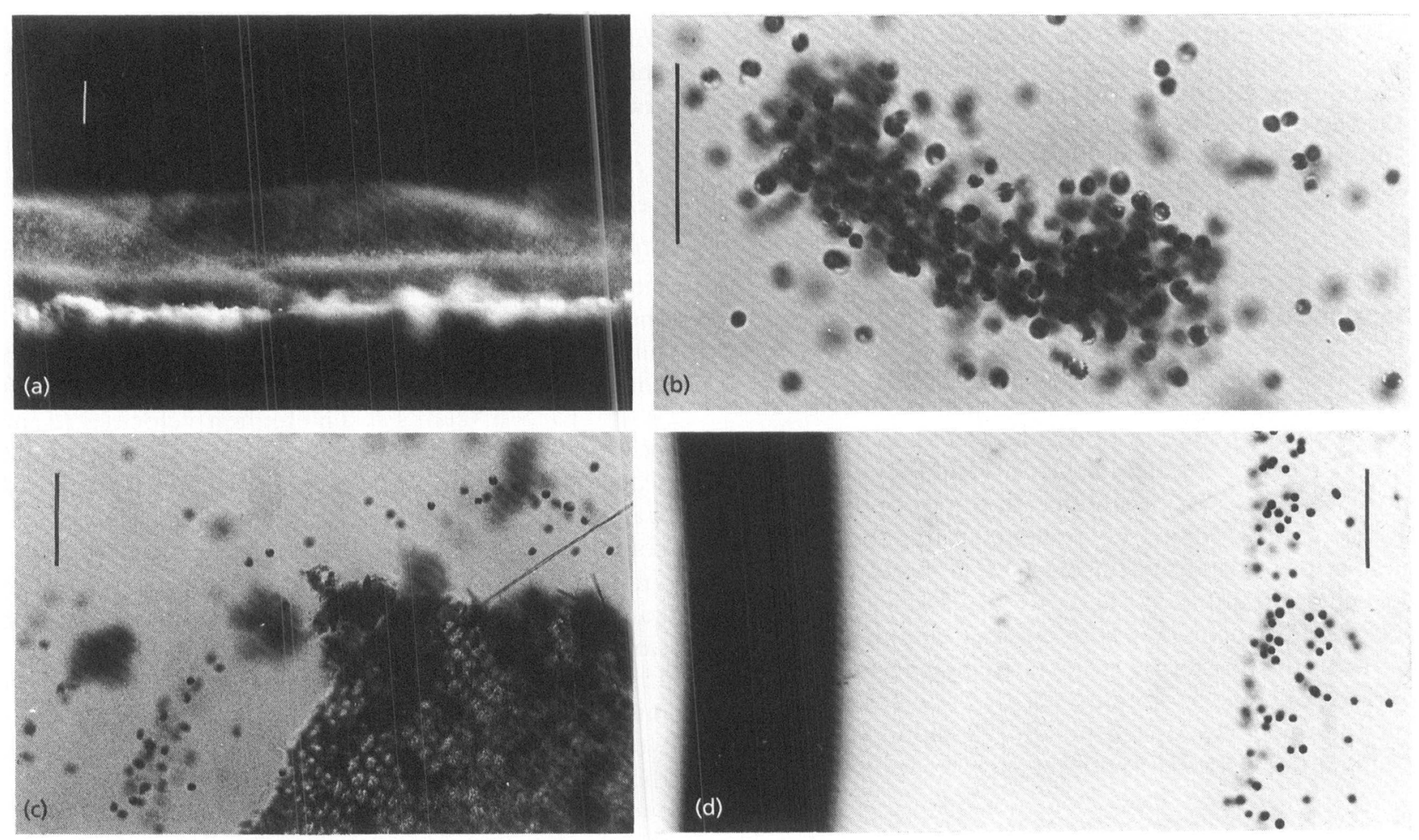

Fig. 3. Distribution patterns of Thiovulum. (a) A veil forming 1-2 mm above a sulphidic sediment in an aquarium; (b) a non-attached aggregation of cells which have become mutually entangled in their mucous stalks; (c) cells attached to a detrital particle (partly decomposed seagrass leaf); (d) a band of Thiovulum cells in a microslide preparation which formed about $600 \mu \mathrm{m}$ from the meniscus (black zone to the left). Scale bars: (a) $2 \mathrm{~mm}$; (b-d) $100 \mu \mathrm{m}$.

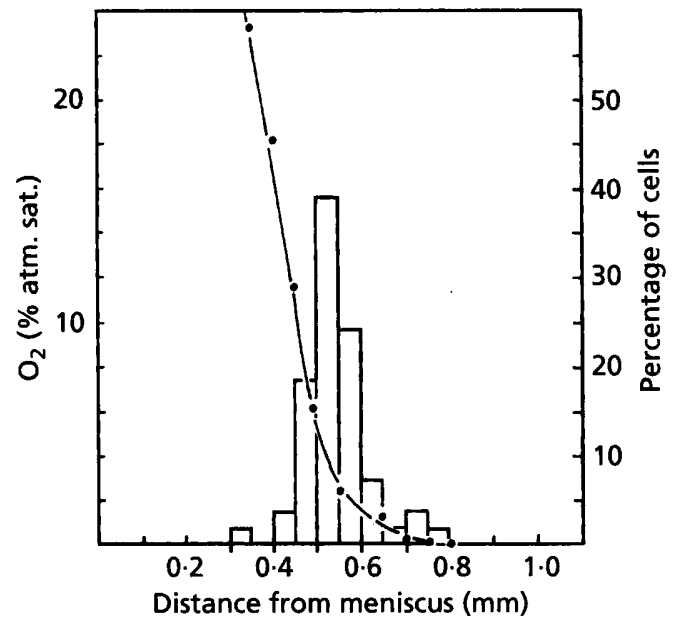

Fig. 4. $\mathrm{O}_{2}$-gradient $(O)$ and the distribution of Thiovulum cells (bars) in a microslide preparation.

\section{Behaviour in gradients}

In capillary microslides the bacteria formed a distinct band (Figs 3d, 4) at some distance from the meniscus. The time taken to form these bands depended on the initial $\mathrm{O}_{2}$ concentration of the water and on the number of bacteria in the suspension. The $\mathrm{O}_{2}$-gradient was linear from the meniscus to the bacterial band; in the band the concentration-gradient curved and $\mathrm{O}_{2}$ was undetectable about $50 \mu \mathrm{m}$ behind the band. This showed that the $\mathrm{O}_{2}$ consumption was predominantly due to the Thiovulum cells.

The maximum density of the band always coincided with an $\mathrm{O}_{2}$-tension of about $4 \%$ atm. sat. $(0.85 \mathrm{kPa})$. The width of the band (defined as \pm one standard deviation and in practice including about $70 \%$ of the cells in the preparation) varied between 80 and $240 \mu \mathrm{m}$ depending on the steepness of the $\mathrm{O}_{2}$-gradient (Fig. 5). The narrow bands spanned from 2 to $8 \%$ atm. sat. If cell densities were too low to maintain a linear $\mathrm{O}_{2}$-gradient of about $5 \%$ per $50 \mu \mathrm{m}$, no distinct bacterial band formed. The presence or absence of sulphide in the anaerobic part of the preparation did not affect the $\mathrm{O}_{2}$-tension preference. No chemosensory response (in terms of aggregation or band formation) occurred in anoxic preparations with or without a sulphide gradient (sulphide was introduced by inserting a seawater-agar plug with 5 or $10 \mathrm{mM}$ neutralized sulphide in the opposite end of the capillary or by mixing the cell suspension with $1 \mathrm{mM}$ neutralized sulphide solution in $\mathrm{O}_{2}$-free seawater before filling the capillaries).

Recorded swimming tracks showed that cells at some distance from the bands swam in random directions. Cells leaving the band, however, swam out to a distance of $150-200 \mu \mathrm{m}$, then made a U-turn and returned in the 


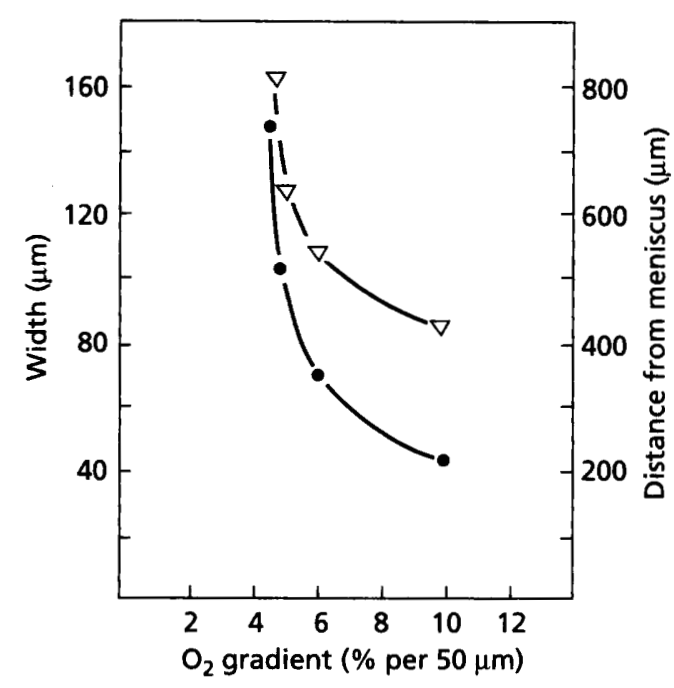

Fig. 5. Width (O, measured as the standard deviation) and distance from meniscus $(\nabla)$ of bacterial bands in microslide preparations as a function of the steepness of the linear part of the $\mathrm{O}_{2}$-gradient.

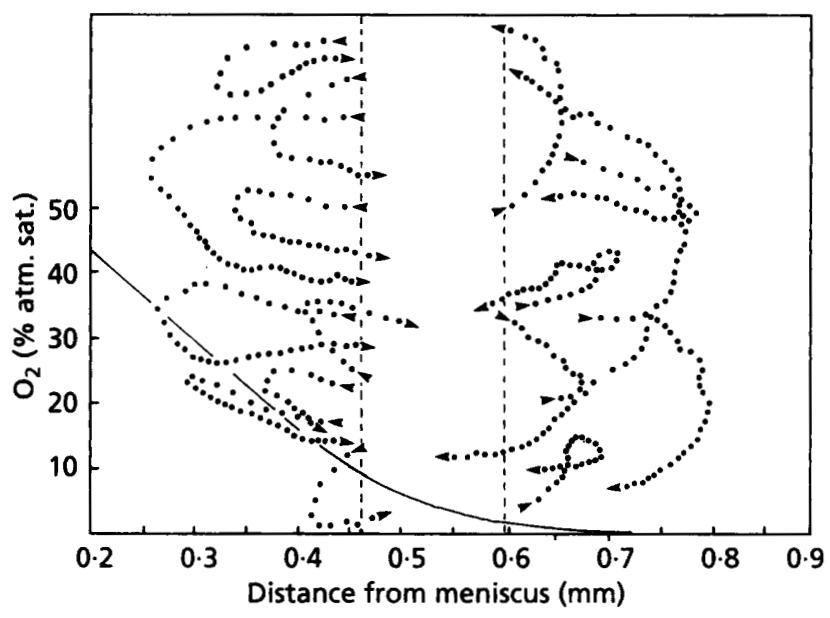

Fig. 6. Sixteen U-turns and the $\mathrm{O}_{2}$-gradient $(-)$ recorded in a microslide preparation. The dashed lines delineate the band (one standard deviation to either side of the mean); time intervals, $\mathbf{4 0} \mathrm{ms}$. The recordings are based on the preparation shown in Fig. 4.

direction from which they came. This behaviour was identical whether the cells swam into the oxic or the anoxic side. The U-turns followed a curve on an almost flat plane. These planes could, of course, have different orientations relative to the plane of the microscopic field. Twenty U-turns were observed almost edge-on (two can be seen in Fig. 6). In these trajectories the paths of the cells as they enter and leave the zone were almost superimposed (on the two-dimensional projections) and parallel to one another. Thus, if the cells left the bacterial band at an acute angle they also entered at an acute angle rather than re-orienting the trajectory relative to the $\mathrm{O}_{2}$-gradient.

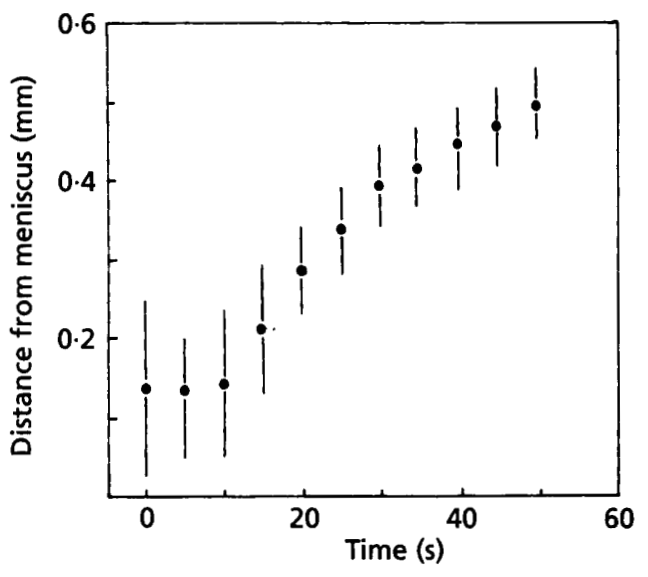

Fig. 7. Retreat of the band (mean \pm one standard deviation) after the $\mathrm{O}_{2}$-tension of the headspace in a microslide preparation was changed from about $10 \%$ atm. sat. to $100 \%$ atm. sat.

Time spent outside the band during each excursion varied between 0.5 and $2 \mathrm{~s}$. Cells which entered the band at an angle approaching $90^{\circ}$ after an excursion to one side often continued through the band and made another $\mathrm{U}$-turn on the other side; cells which entered at a more acute angle often managed to remain for a longer time within the band. Cells which had left the optimum zone succeeded in returning to it after making one U-turn in $>90 \%$ of the recorded tracks. The few cells which failed (mainly cells leaving at an acute angle) did not attempt to turn.

Fig. 6 shows that the U-turn was associated with changes in the parameters describing the swimming path: a decreased translational speed, a decreased pitch and an increased radius, while the period remained unchanged. An analysis of 19 U-turns showed that translational (tangential) velocity decreased by a factor of 0.61 (SE 0.04 ) and that pitch decreased by a factor of 0.55 (SE 0.08) during the turn.

\section{Responses to transient changes in $\mathrm{O}_{2}$-tension}

Cells in capillary microslides could be attracted to the meniscus by a low headspace $\mathrm{O}_{2}$-tension. When the headspace gas was suddenly exchanged with atmospheric air the bacterial band retreated continuously until a new steady-state position was reached after 50-60 s (Fig. 7). This retreat took place at a maximum speed of about $14 \mu \mathrm{m} \mathrm{s}^{-1}$ (or about $2.5 \%$ of the maximum swimming speed).

Attached cells rotated with an angular velocity of about $30 \mathrm{~s}^{-1}\left(5 \cdot 6\right.$ rotations s $\left.{ }^{-1}\right)$. When cells which had attached close $(<100 \mu \mathrm{m})$ to the meniscus were suddenly exposed to higher $\mathrm{O}_{2}$-tensions (by exchanging the headspace gas) nothing happened for a few seconds, corresponding to the time needed for diffusion of $\mathrm{O}_{2}$ from the meniscus. Thereafter, one or more brief changes in the rotational velocity took place; such changes in angular velocity were associated with a bending of the stalk. After one to several 


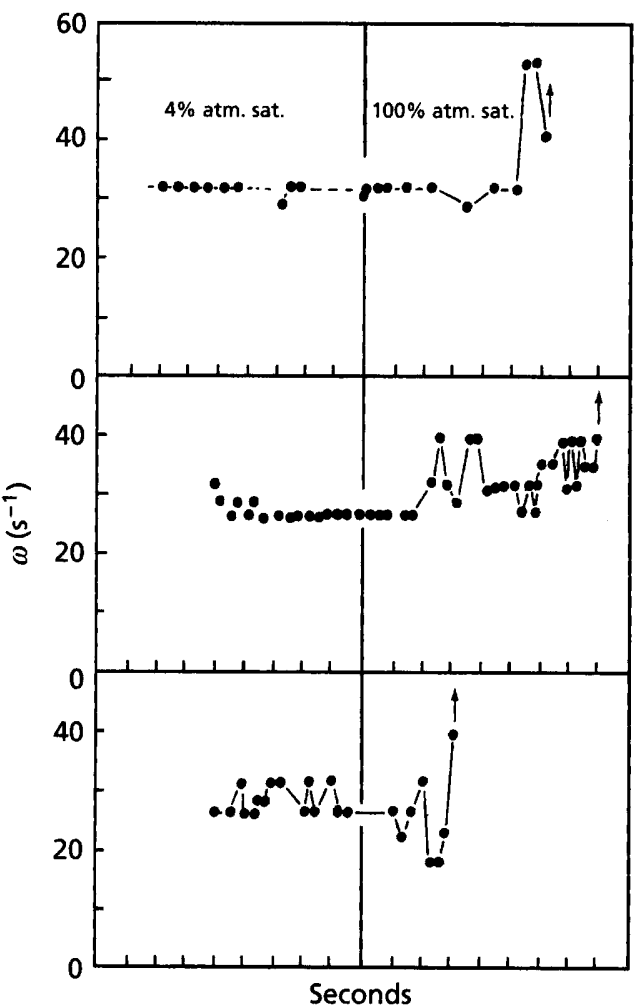

Fig. 8. Rotational velocity of single cells attached close to the meniscus before and after the $\mathrm{O}_{2}$-tension was raised from $4 \%$ atm. sat. to $100 \%$ atm. sat. Arrows indicate when the cells left their stalk and swam off. The units on the $x$-axis represent $1 \mathrm{~s}$.

seconds the cells liberated themselves from the stalk and swam away (Fig. 8).

\section{DISCUSSION}

The present findings confirm earlier studies showing that Thiovulum is a microaerophilic bacterium, but the finding of Jørgensen \& Revsbech (1983) that part of the distribution zone is anoxic could not be supported. The present evidence suggests that the orientation of Thiovulum in chemical gradients is exclusively due to a chemosensory response to $\mathrm{O}_{2}$, and that it does not respond to sulphide concentration. In this respect it is similar to microaerophilic eukaryotic micro-organisms (Fenchel et al., 1989 and references therein).

The swimming speed which can be attained by Thiovulum is unusual among bacteria, which usually swim at velocities around $50 \mu \mathrm{m} \mathrm{s}^{-1}$; Bdellovibrio, which attains swimming speeds somewhat exceeding $100 \mu \mathrm{m} / \mathrm{s}^{-1}$, has been considered to hold the record among bacteria (Armitage et al., 1991). How Thiovulum can swim 5-6 times faster than other bacteria is difficult to explain. The large number of (morphologically typical prokaryote) flagella (see photographs in De Boer et al., 1961, and Wirsen \& Jannasch, 1978) explains how the drag of a larger cell is overcome. But if the hydrodynamics of the flagellar action is as in other bacteria, higher swimming velocities would seem to require that the flagella have a rotational velocity which is correspondingly higher.

It is possible that the ability of Thiovulum to modulate its translational velocity is in part due to the excretion of a mucous thread (which is unattached to a substratum) since this would increase the hydrodynamic drag. Swimming cells with a trailing mucous thread (revealed by attached bacteria) were occasionally observed. If the diameter of the thread was known, this additional drag could readily be calculated on the basis of expressions for the longitudinal drag of a cylinder and for a sphere moving through a viscous fluid (see e.g. Blake \& Sleigh, 1974). The diameter of the anchoring thread must be less than about $0.1 \mu \mathrm{m}$ since it is invisible in the phase-contrast microscope. For a Thiovulum cell with a radius of $7 \mu \mathrm{m}$, a $50 \mu \mathrm{m}$ long trailing thread with a diameter of $0.1 \mu \mathrm{m}$ would increase the drag by about $33 \%$ and the bacterium would swim correspondingly more slowly; if the radius of the thread is smaller, the additional drag would be lower. Trailing mucous threads could therefore play some role in modulating tangential swimming speed, but probably not by the observed factor of 4 . The fact that the cells can also modulate the rotational velocity, indirectly suggests that there is also another mechanism involved in the modulation of translational (tangential) speed.

It has been known since the turn of the century that eukaryotic micro-organisms typically have helical swimming tracks (Jennings, 1901; Blake \& Sleigh, 1974) and it has been generalized that this is the case for all swimming organisms within the size range between 5 and $500 \mu \mathrm{m}$ (Crenshaw, 1993a). It has also been suggested that any organism swimming at low Reynolds number and using some sort of cyclic motile principle (such as flagellar or ciliary motion) will always tend to swim in a helical path (Purcell, 1977). The reason why more typical bacteria (measuring around $1 \mu \mathrm{m}$ ) do not swim in regular helical paths is that they are affected by translational and rotational diffusion (a rotational component of Brownian movement causes angular accelerations of the cells and so affects the precision of swimming). This effect is inversely related to the third power of cell diameter (Berg, 1983). The large Thiovulum cells are therefore much less affected and so have swimming paths which resemble those of eukaryotic micro-organisms.

The mathematics of helical swimming has been treated in detail by Crenshaw (1993a, b) and Crenshaw \& EdelsteinKeshet (1993). This is a complicated topic and some results were achieved through numerical simulations. It was shown that if the translational and rotational velocity components remain constant, then the axis of the swimming will be a straight line and the cell will always orient one side towards the axis. That cells swimming in a helix always face the same side towards the axis has been found empirically in, for example, ciliates (Blake \& Sleigh, 1974; Fenchel \& Jonsson, 1988); it is also likely to be the case for Thiovulum, but it was not possible to demonstrate this. Crenshaw \& Edelstein-Keshet (1993) also found that an acceleration of the rotational velocity component will lead to a bending of the axis and to a permanent change in 
swimming direction as well as a change in radius and pitch of the helix.

The present finding that a change in $\mathrm{O}_{2}$-tension leads to a transient change in rotational velocity in conjunction with the observed changes in the parameters of the swimming tracks during turning suggest that the $\mathrm{U}$-turn response of Thiovulum is accomplished by an acceleration of the rotational velocity when cells move from optimum to adverse conditions.

The 'chemotactic' response of typical bacteria is a klinokinesis. When cells move down a gradient of an attractant they tend to tumble and then swim off in a new (random or almost random) direction; conversely, if they move up the gradient, tumbling is suppressed. This leads to a biased diffusion of the cells and the population will tend to move up the gradient (Macnab \& Koshland, 1972; Berg, 1983; Armitage et al., 1991).

Thiovulum uses two different mechanisms. When outside the optimum zone (at least at high values of $\mathrm{O}_{2}$-tension) the cells swim fast (but in random directions relative to the gradient); under optimum conditions they swim more slowly or even attach themselves to surfaces. Their motility is thus higher under adverse conditions and the statistical probability of finding and remaining in favourable patches is increased. When the cells are relatively far away from the optimum position in the chemocline this orthokinetic response is the only available mechanism of orientation. The other mechanism is the $\mathrm{U}$-turn response, which ensures that once the cells have found an optimum environment they will remain there. If the cells leave the optimum zone they react by turning their swimming path by $180^{\circ}$ and their probability of returning to the optimum zone is almost unity.

This phobic response differs from that of the tumbling of other bacteria in that there is a strong correlation between the swimming direction before and after the response, so there is no statistical element in the effect. This mechanism works in Thiovulum because of the large size of the cells and a correspondingly higher precision in swimming (lower effects of rotational diffusion). There is no evidence that the response reflects any true taxis in the sense that the cells can orient themselves in the gradient. First of all, the response (and distance of the turns) are identical on the oxic and the anoxic side of the bacterial band. In addition, on the anoxic side most turns occur in a zone where $\mathrm{O}_{2}$ was undetectable and therefore there was no $\mathrm{O}_{2}$-gradient to respond to. Furthermore, if cells leave the optimum zone at an acute angle they also return to the zone at an acute angle. If the cells were capable of orienting themselves relative to the gradient, it would be expected that the return path would always tend to have a right angle relative to the plane of the bacterial plate. Crenshaw (1993b) suggested that helical swimming might explain the presence of a genuine tactic response. It could be theoretically shown that if the rotational velocity component is at any time a function of stimulus intensity then the swimming paths may align with a chemical gradient. The present findings do not present evidence that such a mechanism is at work in Thiovulum; the only thing this organism can do is to make a single $180^{\circ}$ turn when swimming from a benign to an adverse environment.

The induction of the U-turn response seems to require some minimum change in stimulus intensity over a limited time period. The width of the band therefore increases with a decreasing steepness of the $\mathrm{O}_{2}$-gradient since cells which leave the zone at an acute angle will then fail to respond, and below some minimum steepness of the gradient a sharply defined veil can no longer be maintained.

The present study explains how Thiovulum cells orient themselves in $\mathrm{O}_{2}$-gradients and how they form and maintain the characteristic veils. It also leaves a number of open questions: the nature of the receptor and transduction involved in the chemosensory response to $\mathrm{O}_{2}$ (but such a response is a widely distributed phenomenon among pro- and eukaryotic micro-organisms and it is in all cases poorly understood) and how the flagella can modulate the rotational and translational motility of the cells.

\section{ACKNOWLEDGEMENTS}

Financial support from the European Union (MAST2-programme, contract no. CT93-0058) and from the Danish Natural Science Research Council (11-0088-1) is gratefully acknowledged. I am also grateful to Jeanne Johansen for technical assistance.

\section{REFERENCES}

Armitage, J. P., Sochett, E. \& Poole, P. S. (1991). Behavioral responses in bacteria. In The Prokaryotes, vol. 1, pp. 241-261. Edited by A. Balows, H. G. Trüper, M. Dworkin, W. Harder \& K.-H. Schleifer. New York: Springer-Verlag.

Berg, H. C. (1983). Random Walks in Biology. Princeton: Princeton University Press.

Blake, J. R. \& Sleigh, M. A. (1974). Mechanics of ciliary locomotion. Biol Rev 49, 85-125.

Crenshaw, H. C. (1993a). Orientation by helical motion. I. Kinematics of the helical motion of organisms with up to six degrees of freedom. Bull Math Biol 55, 197-212.

Crenshaw, H. C. (1993b). Orientation by helical motion. III. Microorganisms can orient to stimuli by changing the direction of their rotational velocity. Bull Math Biol 55, 231-255.

Crenshaw, H. C. \& Edelstein-Keshet, L. (1993). Orientation by helical motion. II. Changing direction of the axis of motion. Bull Math Biol 55, 213-230.

De Boer, W. E., La Rivière, J. W. M. \& Howinck, A. L. (1961). Observations on the morphology of Thiovulum majus Hinze. Antonie Leewwenboek 27, 447-456.

Fauré-Fremiet, E. \& Rouillier, C. H. (1958). Étude aux microscope électronique d'une bactérie sulfureuse, Thiovulum majus Hinze. Exp Cell Res 14, 29-46.

Fenchel, T. \& Jonsson, P. R. (1988). The functional biology of Strombidium sulcatum, a marine oligotrich ciliate (Ciliophora, Oligotrichina). Mar Ecol Prog Ser 48, 1-15.

Fenchel, T., Finlay, B. J. \& Giannì, A. (1989). Microaerophily in ciliates: responses of an Euplotes species (Hypotrichida) to oxygen tension. Arch Protistenkd 137, 317-330. 
Jennings, H. S. (1901). On the significance of the spiral swimming of organisms. Am Nat 35, 369-378.

Jørgensen, B. B. \& Revsbech, N. P. (1983). Colorless sulfur bacteria, Beggiatoa spp. and Tbiovulum sp., in $\mathrm{O}_{2}$ and $\mathrm{H}_{2} \mathrm{~S}$ microgradients. Appl Environ Microbiol 45, 1261-1270.

La Rivière, J. W. M. (1963). Cultivation and properties of Thiovulum majus Hinze. In Symposium on Marine Microbiology, pp. 61-72. Edited by C. H. Oppenheimer. Springfield: Charles C. Thomas Publishers.

Macnab, R. M. \& Koshland, D. E., Jr. (1972). The gradient-sensing mechanism in bacterial chemotaxis. Proc Natl Acad Sci USA 69, 2509-2512.

Purcell, E. M. (1977). Life at low Reynolds number. Am J Pbysics 45, 3-11.

Wirsen, C. O. \& Jannasch, H. W. (1978). Physiological and morphological observations on Thiovulum sp. $J$ Bacteriol 136, $765-774$.

Received 17 March 1994; revised 16 June 1994; accepted 11 July 1994. 